\title{
A abordagem territorial do desenvolvimento rural e suas articulações externas ${ }^{1}$
}

\section{Introdução}

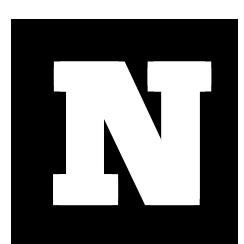

ão deixa de ser surpreendente a velocidade com que ganha espaço público e legitimação a assertiva de que é preciso repensar o modelo de desenvolvimento rural adotado no Brasil e, mais do que isto, reorientar as formas de intervenção do Estado e as políticas públicas. Esta mudança de enfoque começou a ganhar força no Brasil na segunda metade da década de 1990, sob os efeitos de algumas alterações na forma de gestão do Estado, sobretudo com o incremento do papel das recém criadas agências de regulação e da descentralização de algumas políticas públicas federais, fazendo com que os governos locais ganhassem novas atribuições.

No que se refere ao "mundo rural", a percepção da necessidade de uma nova abordagem para a questão do desenvolvimento ganhou fôlego especialmente através da proliferação de idéias e noções que foram importadas para o Brasil por pensadores e estudiosos. Como exemplo deste ideário intelectual que passou a afetar o que Habermas chamou de mundo da vida e a exercer uma influência crescente no debate sobre o desenvolvimento, basta citar a discussão em torno da sustentabilidade e da problemática * Sociólogo, Mestre e Doutor em Sociologia. Pesquisador do CNPq (Bolsa Produtividade em Pesquisa). Professor do Programa de Pós-Graduação em Desenvolvimento Rural e do Departamento de Sociologia da UFRGS. Endereço eletrônico: schneide@ufrgs.br

1 Trabalho apresentado no I Fórum Internacional Território, Desenvolvimento Rural e Democracia, Fortaleza/Ceará, 16, 17, 18, 19 de novembro de 2003, Organizado pelo IICA-Brasil e MDA. 
Sociologias, Porto Alegre, ano 6, no 11, jan/jun 2004, p. 88-125

ambiental, do enfoque local e territorial, das atividades rurais não-agrícolas, das interrelações rural-urbano, entre outros.

Indubitavelmente seria absolutamente equivocado afirmar que os temas que atualmente informam a pauta das discussões sobre as questões rurais e agrárias no Brasil teriam sido majoritariamente colocadas de fora para dentro. De fato, não há dúvida de que a afirmação da agricultura familiar, evidenciada pelo reconhecimento crescente da importância do Programa Nacional de Fortalecimento da Agricultura Familiar (PRONAF), a discussão sobre a imperiosa e difícil tarefa de realizar a reforma agrária e o debate sobre a posição e as oportunidades do setor exportador da agricultura brasileira são exemplos, entre outros, dos vários temas genuinamente domésticos, cuja presença na ordem do dia está relacionada à sua importância concreta e ao seu sentido real para a sociedade brasileira.

$\mathrm{Na}$ interpretação que será apresentada neste trabalho, a análise sobre o desenvolvimento rural e suas articulações externas é entendida como exemplo de uma temática que é retomada no Brasil por força das discussões cada vez mais interessadas em compreender a diversidade de rotas que segue o processo de desenvolvimento e as raízes sociais, econômicas e culturais que explicam essa diversidade. Em verdade, a reflexão sobre as características do desenvolvimento rural e suas articulações exteriores impõe uma discussão prévia sobre o entendimento do próprio desenvolvimento e, em segundo lugar, um posicionamento sobre o sentido de se pensar este processo em termos de um marco espacial e territorial.

Nesse sentido, o presente trabalho pretende refletir sobre o processo de mudança social e econômica que ocorre nos espaços rurais, focalizandoo a partir das experiências acumuladas em estudos anteriores. Na primeira seção do trabalho, serão discutidos os condicionantes mais gerais do processo de restruturação da economia e da sociedade, buscando identificar as relações e as mediações entre os processos locais e as mudanças decorrentes da reestruturação do capitalismo contemporâneo. Na segunda seção, 
discute-se o que alguns autores vêm denominando de novo enfoque do desenvolvimento rural, abordagem esta apoiada no alargamento da abrangência espacial, ocupacional e setorial do rural. Na terceira seção, pretende-se indicar a necessidade de consolidar o deslocamento da idéia de região para a de território, resgatando-se tanto as implicações e resistências a esta operação que vem da geografia como as indicações de alguns estudiosos, organismos internacionais e governos que fazem um uso normativo e operacional da abordagem territorial para indicar um novo enfoque sobre o desenvolvimento regional. À luz dessas discussões, na quarta e última seção, pretende-se analisar as articulações e intermediações das dinâmicas locais e territoriais com o ambiente externo, aqui entendido como o contexto econômico e societário em que transcorrem os processos de mudança social.

\section{Reestruturação capitalista e condicionantes do desenvolvimento rural}

Por mais breve que seja, qualquer caracterização do cenário recente não pode deixar de reconhecer que o quadro atual é profundamente marcado por um processo de ampliação da interdependência nas relações sociais e econômicas em escala internacional. Trata-se dos efeitos e dos condicionantes impostos pela globalização que, sinteticamente, pode ser caracterizada, conforme definiu Castells (1999), pela excepcional capacidade da economia capitalista de ajustar, em escala planetária, a interdependência entre as condições de tempo e espaço no processo global de produção de mercadorias. Essa interdependência se expressa através da descentralização industrial, da velocidade de contato proporcionada pelas novas telecomunicações, através da integração dos capitais financeiros, comerciais, agroindustriais, etc. (Coutinho, 1995).

Também não foge a este contexto a reformulação da arquitetura polí- 
tica e institucional que, desde o final de Segunda Guerra Mundial, dava sustentação ao modelo econômico. Os Estados nacionais e os organismos públicos internacionais, que exerceram papel hegemônico no desenvolvimento capitalista desde meados do século XX, em muitos sentidos perderam esta proeminência e se enfraqueceram (sobretudo pela importância crescente das organizações não governamentais da sociedade civil, de um lado, e do poder das empresas transnacionais, de outro) e, não raro, viramse na contingência de promover mudanças e readequações para não sucumbirem aos novos tempos. Uma das saídas, experimentadas no período mais recente, é o reconhecimento da necessidade de estabelecer parcerias com os governos e instituições locais e valorizar a participação da sociedade civil na gestão de suas ações.

Para dar conta deste amplo espectro de transformações, vários sociólogos têm recorrido ao conceito de reestruturação. Terry Marsden, um dos estudiosos europeus que se tem ocupado com a análise das transformações socioeconômicas globais e seus efeitos sobre a agricultura e o espaço rural, definiu a reestruturação como um processo de transformação global, que pode ser observado mais claramente no setor industrial e se caracteriza pela influência crescente das tecnologias informadas pela microeletrônica e informática, bem como seus impactos sobre as formas de organização produtiva (novos processos de produção) e, conseqüentemente, sobre as relações de trabalho (Marsden et al, 1993; Marsden, Lowe, Whatmore, 1990).

Na perspectiva de Marsden, ao contrário do que muitos autores afirmam, as transformações estruturais do capitalismo, iniciadas no final da década de 1970 nos países capitalistas desenvolvidos e que se internacionalizaram com mais intensidade a partir da década de 1990 após os eventos políticos da queda do Muro do Berlim, seriam a expressão do recuo do regime fordista, modelo até então vigente, baseado na ampliação da produtividade dos fatores de produção (via aprofundamento do progresso técnico) e no papel regulatório do Estado e dos organismos multinacionais (Harvey, 
1993). A nova fase, segundo esse autor, seria caracterizada pela flexibilização dos processos produtivos, pela descentralização das unidades de produção e pela informalização das relações de trabalho, reduzindo-se substancialmente o papel do Estado e das instituições regulatórias.

No que diz respeito à agricultura e ao mundo rural, os efeitos da reestruturação econômica, produtiva e institucional podem ser percebidos através de múltiplas facetas e/ou dimensões. Primeiro, abrem-se os mercados, aceleram-se as trocas comerciais e intensifica-se a competitividade, agora tendo por base poderosas cadeias agroalimentares que monopolizam a produção e o comércio atacadista em escala global, restringindo a participação nestas relações de troca de imensas regiões produtoras, o que vale inclusive para alguns países e mesmo parcelas continentais (Reardon e Berdegué, 2003). Segundo, paralelamente ao processo contínuo de aprofundamento do progresso tecnológico (agora via biotecnologias, engenharia genética, etc.), assiste-se ao aparecimento de iniciativas, dos mais variados matizes, que contestam e criticam o padrão técnico dominante (Goodman e Watts, 1997). Terceiro, as modificações nos processos de produção pós-fordistas (mais flexíveis e descentralizados) levam à diluição das diferenças setoriais (agribusiness é visto pelo encadeamento de vários setores) e espaciais. O rural deixa de ser o locus específico das atividades agrícolas, e as variadas formas de complementação de renda e ocupação em atividades não-agrícolas permite que a renda de muitas famílias que residem no meio rural se estabilizem ao longo do ano e que os filhos não precisem mais deixar o meio rural para achar emprego (OCDE, 1996; Echeverría, 2001; Graziano da Silva, 1999; Schneider, 2003). Quarto, modifica-se o papel do poder público e das instituições que atuam nos espaços rurais, o centralismo cede espaço à parceria e à participação da sociedade (Boisier, 1999; Campanhola e Graziano da Silva, 2000). Quinto, a dimensão ambiental e a sustentabilidade do uso dos recursos naturais deixa de ser vista como um aspecto secundário e um argumento de minorias e passa a 
ser um fator de competitividade, um elemento de estímulo à ampliação do consumo, uma vantagem econômica comparativa e um pré-requisito para obtenção de créditos e acesso a fundos de investimento, especialmente os de fontes públicas (Ploeg e Renting, 2000).

É claro que a lista dos efeitos e resultados da reestruturação poderia ser alongada. Contudo, para o interesse específico deste trabalho, considera-se que estas características sejam os elementos essenciais que devem ser levados em consideração na discussão das perspectivas atuais do desenvolvimento rural. Sobretudo quando esta reflexão deve ser informada pelo papel que exercem e o modo como se dão as articulações entre este contexto mais geral e as dinâmicas locais dos processos produtivos e a ação dos atores sociais.

\section{Para uma definição do desenvolvimento rural}

Uma análise apropriada dos processos de mudança socioeconômicos que têm lugar nos espaços rurais e seus articuladores externos requer o enfrentamento da espinhosa tarefa de definir o que se entende por desenvolvimento rural.

Em face das transformações societárias que se operaram a partir do processo mais geral de reestruturação econômica e institucional que vem se aprofundando nos anos recentes, vários analistas passaram a preconizar a necessidade de repensar as abordagens analíticas e os enfoques que até então eram utilizados como referências teóricas para definir o desenvolvimento rural.

Fora do Brasil, a discussão sobre o desenvolvimento rural tem recuperado seu espaço e animado tanto discussões teóricas e analíticas quanto seus efeitos normativos e institucionais. Analisando-se alguns dos trabalhos e autores referenciais nesse debate recente, ressalta-se a preocupação dos estudiosos com quatro elementos-chave a partir dos quais se preconiza a 
retomada do debate sobre o desenvolvimento rural: a erradicação da pobreza rural, a questão do protagonismo dos atores sociais e sua participação política, o território como unidade de referência e a preocupação central com a sustentabilidade ambiental.

Esta busca por referenciais alternativos e inovadores parece ser uma prática recorrente, sobretudo em se tratando do desenvolvimento rural. Aliás, não seria tarefa difícil identificar uma literatura considerável que, a todo momento, propõe-se a oferecer novos approaches (aportes). No período recente, as várias tentativas de síntese e esboço de novos referenciais sempre acabam enfatizando a necessidade de se estabelecer deslocamentos de enfoque, quer seja do produtor/agricultor para as redes de atores (actor-network), do setor agrícola (ou da agricultura) para o espaço rural alargado, das ações do tipo blueprint ou top-down para as de bottom-up, grassroots, abajo-arriba, entre outros.

Esta tendência convergente em torno da preocupação constante em sugerir deslocamentos é ainda mais forte no que se refere à noção de território. De fato, entre os estudiosos parece haver um certo consenso de que esta talvez seja a unidade de referência mais adequada para se estudar e analisar os processos gerais de reestruturação societários e seus impactos locais. Sem a pretensão de fazer um apanhado geral do estado da arte desse debate, na seqüência, pretende-se sintetizar as idéias de alguns autores cujos trabalhos parecem oferecer uma contribuição importante para redefinição do desenvolvimento rural na perspectiva territorial.

Um dos autores a propor uma nova abordagem para o desenvolvimento rural, particularmente em países em desenvolvimento, é do inglês Frank Ellis $(2001 ; 2000 ; 1998)$. Sua abordagem privilegia o que denomina de estratégias de sobrevivência familiares e a diversificação dos modos de vida rurais (household strategies and rural livelihood diversification), mostrando que as iniciativas e ações que geram impactos significativos na melhoria das condições de vida dessas populações e que ampliam suas perspectivas 
de garantir a reprodução social e econômica estão, na maioria das vezes, nas próprias localidades e territórios onde vivem. A diversificação não implica apenas ampliação das possibilidades de obtenção de ingressos, especialmente rendas (agrícolas, não-agrícolas, outras), mas representa, sobretudo, uma situação em que a reprodução social, econômica e cultural é garantida mediante a combinação de um repertório variado de ações, iniciativas, escolhas, enfim, estratégias. Ellis é cuidadoso e refratário quanto à atribuição de um sentido teórico à noção de desenvolvimento rural, preferindo definilo como um conjunto de ações e práticas que visam reduzir a pobreza em áreas rurais, visando estimular um processo de participação que empodera (empowerment) os habitantes rurais, tornando-os capazes de definir e controlar suas prioridades para a mudança (2000, p. 25; 2001, p.443).

Embora sem estabelecer diálogo aparente com a perspectiva anterior, a abordagem do desenvolvimento rural sugerido pelo holandês Jan Douwe Van Der Ploeg et al. (2000, Ploeg and Dijk, 1995) apóia-se no que chama de teoria empiricamente fundamentada (empirically grounded theory) e apresenta vários elementos semelhantes aos sugeridos por Ellis sendo, contudo, mais voltada para os problemas e o contexto dos países desenvolvidos. Ploeg também reconhece que os esforços em definir conceitualmente o desenvolvimento rural fracassaram, podendo-se, no entanto, afirmar que a noção de desenvolvimento rural emerge dos debates e disputas sociais e políticas. Para uma definição do desenvolvimento rural a partir das práticas e ações empíricas, Ploeg et al indicam a necessidade de reconhecê-lo como um processo de múltiplos níveis assentado na tradição histórica (2000, p. 391).

Estes múltiplos níveis da nova abordagem do desenvolvimento rural estariam apoiados em seis mudanças gerais, todas elas relacionadas aos limites e problemas decorrentes do modelo agrícola produtivista (assentado nos princípios da "revolução verde"), que estaria em fase de superação. Primeiro, o crescente interrelacionamento da agricultura com a sociedade, fazendo com que esta perceba que o rural pode fornecer muito mais do 
que alimentos e matérias-primas. Segundo, uma necessidade urgente em definir um novo modelo agrícola que seja capaz de valorizar as sinergias e a coesão no meio rural, entre atividades agrícolas e não-agrícolas, entre ecossistemas locais e regionais, permitindo a convivência de iniciativas e atividades diversificadas. Terceiro, um desenvolvimento rural capaz de redefinir as relações entre indivíduos, famílias e suas identidades, atribuindo-se um novo papel aos centros urbanos e à combinação de atividades multiocupacionais, com claro estímulo à pluriatividade. Quarto, um modelo que redefina o sentido da comunidade rural e as relações entre os atores locais, sejam eles os agricultores ou os novos usuários (proprietários de sítios de lazer, moradias secundárias, empresas, condomínios, etc.). Quinto, um desenvolvimento rural que leve em conta a necessidade de novas ações de políticas públicas e o papel das instituições, que não podem ser mais exclusivamente direcionados à agricultura. Sexto, e último, levar em consideração as múltiplas facetas ambientais, buscando garantir o uso sustentável e o manejo adequado dos recursos.

Neste sentido, segundo Ploeg et al. (2000, p. 395), o desenvolvimento rural seria uma tentativa de reconstrução das bases econômicas, sociais e ambientais, e das próprias unidades familiares, em face das limitações e lacunas intrínsecas do paradigma produtivista. Em síntese, como dispositivo heurístico, o desenvolvimento rural representaria uma possibilidade de ir além da modernização técnico-produtiva, apresentando-se como uma estratégia de sobrevivência desenvolvida por unidades familiares rurais que buscam, através de seu esforço e disposições, incrementar as possibilidades de garantir sua reprodução (Ploeg et al 2000, p. 396). Nesta nova abordagem do desenvolvimento rural ganha especial relevo o papel dos agricultores, que passam a orientar suas práticas produtivas não mais segundo o padrão agricultor-empresário profissional mas, crescentemente, para o modelo de um agricultor-camponês, que é autônomo, domina tecnologias, toma decisões, controla e gestiona processos, enfim, decide sobre seu modo 
de viver e trabalhar nos marcos de uma sociedade capitalista.

Entre os autores brasileiros, as tentativas de definir o que se entende por desenvolvimento rural podem ser sintetizadas a partir de duas contribuições principais. Primeiro, a partir dos trabalhos de José Eli da Veiga, que focaliza as dimensões ambientais e territoriais do desenvolvimento rural. Em suas publicações mais recentes (Veiga et al 2001; Veiga, 2001), o autor não arrisca uma definição para o desenvolvimento rural, preferindo destacar suas interfaces e vínculos em relação ao desenvolvimento em geral (sobretudo a necessidade de conceber o desenvolvimento rural e urbano de forma interconectada), que é entendido a partir da perspectiva avançada por Amartya Sen, que o define como "um processo de expansão das liberdades substantivas dirigindo a atenção para os fins que o tornam importante e não para os meios..." (Sen apud Veiga, 2001). Nesta perspectiva, de expansão das capacitações individuais e melhoria dos funcionamentos, Veiga aponta como elementos fundamentais do processo de desenvolvimento rural a valorização e fortalecimento da agricultura familiar, a diversificação das economias dos territórios (sobretudo através do estímulo aos setores de serviços e à pluriatividade), o estímulo ao empreendendorismo local e o empurrão que viria do Estado para formação de arranjos institucionais locais como os elementos-chave para a nova estratégia de desenvolvimento rural sustentável do Brasil (et al. 2001; 2001).

Em trabalhos anteriores (Veiga, 1998, p. 11), a definição de desenvolvimento de Veiga caracterizava-o como "um processo sistêmico mediante o qual uma economia consegue simultaneamente crescer, reduzir desigualdades sociais e preservar o meio ambiente (acrescentando: fácil de falar, difícil de conseguir)". E especificamente o desenvolvimento rural foi então definido como um fenômeno intrinsecamente local e regional. As localidades e regiões que melhor conseguissem desenvolver-se seriam aquelas que apresentariam maior capacidade de organizar os fatores endógenos, direcionando-os para o fortalecimento da organização social, para o aumento da autonomia local dos atores na 
tomada de suas decisões, para a capacidade de reter e reinvestir capitais em nível local, enfim, para promover a inclusão social e o aumento da capacidade de regenerar e conservar o meio ambiente (idem, p. 26).

O segundo autor brasileiro que procurou aportar uma definição para o desenvolvimento rural é Navarro $(2002 ; 2001 ; 1999)$. Na sua opinião, o ressurgimento do debate em torno da noção de desenvolvimento rural estaria relacionada com as inquietações sociais, típicas da época atual, em que mais do que haver clareza sobre seu significado e características, o que existe é uma incógnita em relação à sua própria possibilidade. Segundo Navarro, as complexas mudanças societárias, associadas à globalização, teriam gerado incertezas e riscos, retirando o debate sobre o desenvolvimento tout court da penumbra em que se encontrava até recentemente. Como ponto de partida, Navarro propõe uma distinção conceitual entre o desenvolvimento agrícola (associado às condições de produção agropecuárias), o agrário (associado à vertente teórica marxista) e o rural, sendo que o último deveria ser entendido de forma meramente operacional, a posteriori, como análise das ações do Estado dirigidas ao meio rural ou como uma ação prática dirigida para implantar programas que estimulem alterações socioeconômicas no futuro. Assim, para Navarro, a noção de desenvolvimento rural restringe-se ao seu uso prático e normativo, com a finalidade de caracterizar estratégias e ações do Estado que visam alterar e/ou melhorar as condições de vida no meio rural.

Como se percebe, apesar de muito difundida e utilizada, a noção de desenvolvimento rural continua a ser de definição complexa e multifacetada, passível de ser abordada por perspectivas teóricas das mais diversas. Mesmo assim, de modo amplo, neste trabalho, o desenvolvimento rural é definido como um processo que resulta de ações articuladas, que visam induzir mudanças socioeconômicas e ambientais no âmbito do espaço rural para melhorar a renda, a qualidade de vida e o bem-estar das populações rurais. Dadas as especificidades e particularidades do espaço rural determinadas 
pelos condicionantes sociais, econômicos, edafo-climáticos e tecnológicos, o desenvolvimento rural refere-se a um processo evolutivo, interativo e hierárquico quanto aos seus resultados, manifestando-se nos termos dessa complexidade e diversidade no plano territorial.

\section{Do desenvolvimento regional ao desenvolvimento territorial}

Conforme antes salientado, as diferentes perspectivas analíticas que trabalham com o tema do desenvolvimento rural parecem atribuir um significado cada vez mais relevante ao enfoque territorial, que começa a figurar como uma importante unidade de análise conceitual e de referência normativa entre os estudiosos do tema.

A emergência da abordagem territorial do desenvolvimento rural pressupõe que o nível adequado de tratamento analítico e conceitual dos problemas concretos deva ser o espaço de ação em que transcorrem as relações sociais, econômicas, políticas e institucionais. Esse espaço é construído a partir da ação entre os indivíduos e o ambiente ou contexto objetivo em que estão inseridos. Portanto, o conteúdo desse espaço é entendido como o território. Mas não se trata apenas do entendimento teórico e abstrato, pois esta perspectiva também propõe que as soluções e respostas normativas aos problemas existentes nesses espaços encontram-se nele mesmo.

No Brasil, a abordagem territorial vem ganhando rápido interesse, especialmente no âmbito dos planejadores e formuladores de políticas públicas, haja vista a criação de uma Secretaria de Desenvolvimento Territorial, ligada ao Ministério do Desenvolvimento Agrário (MDA), e uma significativa simpatia de outros órgãos governamentais em torno das potencialidades normativas do novo aporte. ${ }^{2}$ Em face da situação presente, cabem duas indagações fundamentais: quais são os fatores ou motivos que levaram à emergência da abordagem territorial do desenvolvimento rural e quais são 
as implicações ou desdobramentos que sua adoção pode acarretar, especialmente no que se refere às suas ligações ou articulações com o exterior. Esta última questão será tratada em maior detalhe no próximo item.

No que se refere à indagação acerca dos fatores que ocasionaram a emergência da abordagem territorial como tentativa de síntese para as discussões sobre o desenvolvimento rural, é possível afirmar que a origem está em dois processos distintos. Primeiro, pelo esgotamento teórico e prático da abordagem regional, que torna evidentes os limites da noção de região como unidade de referência para se pensar as ações e políticas públicas destinadas à promoção do desenvolvimento rural.

O desgaste da noção de região e, mais precisamente, de desenvolvimento ou planejamento regional, inicia-se com a crise da capacidade de intervenção macroeconômica e macrossocial do Estado, que ocorre a partir de meados da década de 1970 e se agudiza na década seguinte, especialmente com a influência crescente do ideário neoliberal sobre as perspectivas keynesianas que vigoravam desde o final da Segunda Guerra Mundial.

Não se trata aqui de apresentar uma longa digressão sobre o assunto, mas vale lembrar que, na geografia clássica o conceito de região defendido por Paul Vidal de La Blache fazia referência às qualidades de relevo, clima, geologia, localização, entre outros, que caracterizavam determinados espaços habitados e utilizados com finalidades econômicas por uma determinada população. Aos poucos, essa noção de região tornou-se, ao mesmo tempo, um instrumento analítico para descrever as características naturais dos espaços, permitindo sua classificação e tipificação, e uma ferramenta com finalidades normativas, pois, mediante o conhecimento das características geográficas de um espaço determinado, tornou-se possível estimar, medir e comparar a eficiência econômica com que os homens faziam uso dos recursos nele disponíveis, podendo-se tomar como exemplo a atividade agropecuária.

2 Para uma apreciação a este respeito consultar o documento de trabalho "Referências para um programa territorial de desenvolvimento rural sustentável", publicado pelo MDA/SDT/CONDRAF, produzido pelo IICA, versão de setembro de 2003. 
Assim, tornou-se possível medir a geração de riqueza segundo regiões distintas (micro, meso e macro passaram a ser as escalas regionais mais utilizadas) de países e continentes, calcular seu tamanho e comparar, ao longo do tempo, a evolução de seu crescimento. Portanto, regiões desenvolvidas passaram a ser aquelas que apresentavam indicadores favoráveis de crescimento como os demográficos, educacionais e, sobretudo, econômicos (medidos pelo PIB, renda per capita, etc.). E foi por este viés que se orientaram as ações de planejamento e atuação do Estado, via políticas públicas, visando estimular o crescimento nas diferentes regióes, privilegiando especialmente as áreas urbanas pela simples razão de que, nestas, as respostas dos agentes econômicos aos estímulos externos eram mais favoráveis e se traduziam mais rapidamente em incremento nas taxas de crescimento. Em síntese, pode-se dizer que a visão urbana e industrial do desenvolvimento assenta-se numa concepção analítica e operacional que toma a noção de região como unidade de referência.

Contudo, a partir de meados da década de 70 e, mais especialmente, durante a década de 80, quando novos critérios de julgamento e avaliação do que poderia ser definido como desenvolvimento, tais como as noções de sustentabilidade ambiental e qualidade de vida, passaram a vigorar e a se legitimar, assiste-se a mudanças significativas em relação ao conteúdo conceitual e normativo da noção de região. Como se sabe, há farta literatura indicando o anacronismo da idéia de que o desenvolvimento se restringe ao crescimento econômico e que, portanto, regiões desenvolvidas podem não ser aquelas que fazem uso eficiente dos fatores de produção. Mais do que isso, a mudança de critérios e métodos de abordagem do desenvolvimento também modificou a atuação normativa dos agentes, das instituições e do próprio Estado, cuja ação indutora ou intervencionista deixou de ter na região uma unidade de análise segura e capaz de garantir resultados eficientes. Em resumo, a abordagem regional perde seu poder explicativo enquanto referência teórica e conceitual e tornou-se insuficiente como instrumento para o planejamento 
normativo das ações práticas do Estado e dos agentes políticos.

É neste contexto que ganha relevo o território, agora como uma noção com estatuto operacional que permite a superação dos condicionantes e limites do aporte regional. Mas o território que reemerge não tem nada a ver com o conteúdo geopolítico da definição de Estado-Nação que lhe conferira originalmente o geógrafo alemão Friedrich Ratzel. "O retorno do território", como aludiu Milton Santos (1994), está relacionado às mudanças socioespaciais e político-institucionais do capitalismo em sua fase pósfordista (Harvey, 1993). Trata-se dos efeitos mais gerais da reestruturação dos processos produtivos, que não apenas se internacionalizam (ou globalizam), mas também recompõem e afetam os territórios e as localidades que são a projeção particular sobre um espaço determinado. Neste sentido, o território emerge como um processo vinculado à globalização, sobretudo porque a nova dinâmica econômica e produtiva depende de decisões e iniciativas que são tomadas e vinculadas em função do território.

Mais ainda, o território emerge como nova unidade de referência para a atuação do Estado e a regulação das políticas públicas. Trata-se, na verdade, de uma tentativa de resposta do Estado, entendido como instituição jurídico-social, às fortes críticas a que vinha sendo submetido, sobretudo tendo em vista a ineficácia e a ineficiência de suas ações, seu alto custo para a sociedade e a permanência das mazelas sociais mais graves como a pobreza, o desemprego, a violência, etc.

Neste cenário, ganham destaque iniciativas como a descentralização das políticas públicas; a valorização da participação dos atores da sociedade civil, especialmente ONGs e os próprios beneficiários; a redefinição do papel das instituições; e cresce a importância das esferas infranacionais do poder público, notadamente as prefeituras locais e os atores da sociedade civil. Contudo, para acionar e tornar efetivas as relações do Estado central com esses organismos locais, tornou-se necessário forjar uma nova unidade de referência, que passou a ser o território e, conseqüentemente, as ações 
de intervenção decorrentes deste deslocamento passaram a se denominar desenvolvimento territorial.

O segundo fator que pode ser arrolado como motivo importante para a emergência da abordagem territorial está baseado no questionamento crescente da dinâmica setorial de ramos da atividade econômica que passaram a se desenvolver muito mais a partir de uma lógica de escopo do que de escala. Em suas revisões sobre a origem da abordagem territorial, dois trabalhos recentes (Vázquez Barquero, 2001 e Schejtman e Berdegué, 2003) destacam o papel das transformações econômicas e o aparecimento de perspectivas de análise destes processos relacionados ao enfoque do desenvolvimento endógeno ou territorial.

Ambos os autores privilegiam o entendimento de como a abordagem territorial foi apropriada e introduzida nas análises sobre o desenvolvimento econômico. Vázquez Barquero (2001) indica que, a partir da década de 80, confluíram duas vertentes do pensamento econômico que hoje formam a base do que ele denomina de paradigma do desenvolvimento territorial endógeno. De um lado, alguns herdeiros da perspectiva neoclássica (Robert Lucas, Paul Krugman, etc.) buscavam uma maneira de incorporar a noção de espaço ao desenvolvimento econômico e explicar o papel das externalidades (inovação tecnológica, papel das instituições, educação, etc.) para compreender as razões que levam à evolução ou ao atraso das regiões. A outra vertente, mais empírica, surge a partir dos trabalhos de cientistas sociais italianos (Becattini, Bagnasco, Garofoli, etc.), sobretudo economistas, preocupados em compreender as especificidades da industrialização da região da Terceira Itália, localizada no centro-sul do país (Emilia-Romagna, Toscana, etc.). Essa vertente ganhou projeção a partir da formulação da tese de Piore e Sabel (1984), que indicaram que o processo italiano sinalizava a emergência de um novo modelo de organização dos processos produtivos industriais, denominado de especialização flexível, que representaria um avanço em relação ao fordismo. 
Na década de 80, os estudos sobre a industrialização difusa na Itália ganharam excepcional projeção internacional, levando à retomada da idéia de distritos industriais, de A. Marshall, ${ }^{3}$ agora sob o enfoque das economias locais de proximidade (clusters) e do papel dos territórios (o milieu ou entorno). Os trabalhos de Becattini (apud Vázquez Barquero, 2001) e Bagnasco (1996; 1993), entre tantos outros, indicaram que a especificidade do caso italiano residia na formação de sistemas produtivos com forte identificação das empresas e dos agentes econômicos, com os territórios em que estavam localizados. Assim, os territórios passam a ser agentes de transformação social e não um mero suporte de recursos físicos para objetos, atividades e processos econômicos (Vázquez Barquero, 2001, p. 58).

Os sistemas produtivos locais, gerados a partir de processos endógenos de desenvolvimento territorial, operam com base em relações de trabalho e de produção peculiares que estão diretamente relacionados ao ambiente social e à estrutura econômica, permitindo assim uma articulação das novas formas de produção com o modo de vida local. Essa articulação do tecido produtivo local com o ambiente socioeconômico levou à crescente utilização do conceito de entorno (ou milieu, conforme referiram Maillat, 1996 e Aydalot, 1986, apud Vázquez Barquero, 2001), entendido como o espaço (físico, mercantil, cultural, identitário, etc.) onde se dá a atuação dos agentes. De fato, o milieu possui a conotação e passa a ser entendido como o território. Seguindo esta perspectiva, José Reis definiu os territórios como espaços organizadores de funções econômicas, onde se iniciam, desenvolvem-se e se potencializam processos relacionais de estruturação produtiva, originando materialidades econômicas particulares em cujo contexto de funcionamento as referências de ordem local podem ser significativas (Reis, 1992).

À medida que a noção de desenvolvimento territorial se foi fortalecendo, as discussões sobre o papel da agricultura e do espaço rural também se modificaram. Na verdade, a abordagem territorial promoveu a superação do 
enfoque setorial das atividades econômicas (agricultura, indústria, comércio, serviços, etc.) e suplantou a dicotomia espacial entre o rural versus urbano ou o campo versus cidade. Na perspectiva territorial, as dicotomias e os antagonismos são substituídos pelo escrutínio da diversidade de ações, estratégias e trajetórias que os atores (indivíduos, empresas ou instituições) adotam visando sua reprodução social e econômica. Não há determinismo de qualquer ordem ou evolução predeterminada, pois a viabilização dos atores e dos territórios dependerá do modo particular e específico de cada tipo de interação, das decisões e racionalidades. Como resultado, emergem a diversidade e a heterogeneidade social e econômica dos territórios, que se constituem no traço característico dos distintos caminhos e trajetórias que podem ser seguidos em direção ao desenvolvimento (Pecqueur, 1992; 1996).

Em parte beneficiando-se desta discussão mais geral sobre a necessidade de se estabelecer um novo aporte teórico para o desenvolvimento, Schejtman e Berdegué (2003) empreenderam um esforço pioneiro e relevante na tentativa de instrumentalizar a abordagem territorial, mediante sua tradução para o que designaram de teoria da ação normativa do desenvolvimento rural. Em seu trabalho, o desenvolvimento territorial rural é definido como um processo de transformação produtiva e institucional em um espaço rural determinado, com a finalidade de reduzir a pobreza rural. Segundo esses autores, para se tratar o desenvolvimento rural na perspectiva territorial é necessário levar em consideração sete elementos. Primeiro, é num ambiente cada vez mais competitivo que se dão as chances de sobrevivência das unidades de produção. Segundo, a inovação tecnológica continua a ser uma variável-chave para elevar a produtividade da mão-de-obra e as rendas da população rural. Terceiro, a competitividade é um fenômeno sistêmico e depende dos ambientes e dos territórios. Quarto, a demanda externa exerce um apelo decisivo sobre as transformações produtivas locais e territoriais. Quinto, os vínculos rural-urbanos são fundamentais ao desenvolvimento de atividades agrícolas e não-agrícolas em um território. Sexto, o desenvolvimento 
institucional tem importância fundamental para o desenvolvimento dos territórios. Sétimo, o território não é um espaço físico objetivamente existente, mas uma construção social, isto é, um conjunto de relações sociais que se originam e se expressam em uma identidade e em um sentimento de pertencimento compartilhado por agentes públicos e privados.

Com base nestas premissas, a implementação de programas e ações de desenvolvimento territorial rural se tornariam capazes de produzir transformações produtivas e institucionais simultaneamente, ampliar o conceito de rural para além da agricultura e valorizar a heterogeneidade dos territórios, bem como sua capacidade endógena de desenvolver capacitações e iniciativas assentadas na sua identidade socialmente legitimada. Para não seguir fazendo "más de lo mismo", Schetjman e Berdegué sugerem que o desenvolvimento territorial rural requer uma nova arquitetura institucional em que o Estado e a sociedade civil passem a atuar de forma combinada e complementar em múltiplos sentidos. Recomendam igualmente considerar que a superação de problemas estruturais, relacionados às desigualdades e à pobreza rural, podem seguir caminhos distintos (incremento tecnológico, migrações, busca de ocupações não-agrícolas e até mesmo políticas compensatórias) e, mesmo assim, nem sempre passíveis de solução no curto prazo.

Para além dos fatores que determinaram a emergência da abordagem territorial, resta um questionamento decisivo sobre as implicações de sua adoção para se pensar os processos de desenvolvimento rural, especialmente em relação às suas ligações ou articulações externas.

\section{Os territórios e suas articulações externas}

Conforme já antecipado, o objetivo deste texto é contribuir com a reflexão sobre o deslocamento de enfoque a partir do qual se está abordando o desenvolvimento rural. Como se destacou, no período recente, em 
face de mudanças estruturais que ocorreram na sociedade e na economia e mesmo nas perspectivas teóricas, o aporte territorial vem obtendo especial atenção.

Embora já haja experiências internacionais relevantes no uso normativo desta abordagem (entre outros, poder-se-ia citar o caso do Programa LEADER, na União Européia), no Brasil, como de resto nos demais países do continente latino-americano, o estágio destas iniciativas é ainda embrionário. Mesmo sem pretender antecipar críticas ou apontar limitações sobre iniciativas que recém começam a esboçar experimentações efetivas, a título de debate e discussão, podem ser levantadas algumas questões relevantes.

A primeira delas é sobre o estatuto conceitual do território e a adequação de seu uso para finalidades normativas e práticas. Não se pode desconsiderar que o uso conceitual do território é reivindicado por uma disciplina, a Geografia, e que sua utilização atende, antes de tudo, a finalidades heurísticas e analíticas. Todavia, o intercâmbio de conceitos e noções entre os campos acadêmico e normativo é prática corriqueira e, por si só, não representaria obstáculo à utilização do território para fins políticos e práticos. Entretanto, cabe aos usuários explicitar em que sentido recorrem ao território, se conceitual ou normativo ou ambos ao mesmo tempo.

Entre os geógrafos, Guy Di Méo (1998), autor de um livro referencial nesta discussão, afirma que "o território é uma construção social, um processo de interação das relações cotidianas e na co-presença de pessoas entre elas, com os lugares e os objetos". Outro geógrafo, Claude Raffestin (1986; 1987; 1993), define o território como um "conjunto de relações mantidas pelos homens, enquanto membros de uma sociedade, com a extensividade e alteridade mediante a ajuda dos mediadores". Como se percebe, para ambos os autores, o território envolve um processo de interação entre o espaço e a ação humana, que se expressa na forma de uso e nas alterações que o agir dos indivíduos produz sobre a base física e natural em que se encontra. Trata-se, portanto, de uma construção. Mas, conforme ressaltado por 
outros geógrafos (Souza, 2003; Haesbaert, 1997 e 2002), o território não é apenas a expressão do espaço social construído em que ocorre a produção e interação humana, mas é também um campo de forças onde atuam e operam as relações de poder e dominação.

Mesmo sem ser geógrafo, a contribuição de Abramovay sobre o território parece aproximar-se destas definições ao afirmar que os

territórios podem ser definidos como lugares de interação entre sociedades humanas e ecossistemas. O território é a maneira como uma determinada sociedade se organiza em sua relação com a natureza. Esta organização supõe formas de coordenação entre organizações sociais, atores econômicos e representantes políticos necessariamente específicas e com uma história própria a cada lugar. No meio rural a noção de território adquire uma dupla importância: em primeiro lugar, ela convida a reflexão sobre o desenvolvimento a voltar-se a um conjunto variado de protagonistas e a superar assim um âmbito estritamente setorial. A diversificação das economias rurais é, portanto, o resultado mais importante do desenvolvimento territorial em áreas não densamente povoadas. Além disso, a noção de território, no meio rural, chama a atenção ao fato de que o processo de desenvolvimento depende fundamentalmente da maneira como cada localidade vai relacionar-se com os ecossistemas em que vive (2003). ${ }^{4}$

Como se percebe, a definição do que se entende por território está assentada na definição das relações dos indivíduos com o espaço em que transcorre sua sociabilidade e suas atividades produtivas e nas formas de apropriação e dominação que decorrem dessas relações. Assim definido,

4 Abramovay destaca a possibilidade de que esta inter-relação permita que a população rural tire proveito do dinamismo que as cidades tendem a propagar ao seu redor (1998). A idéia central, segundo o autor, "é que o território, mais que simples base física para as relações entre indivíduos e empresas, possui um tecido social, uma organização complexa de laços que vão além de seus atributos naturais, dos custos de transportes e de comunicações. Um território representa uma trama de relações com raízes históricas, configurações políticas e identidades que desempenham um papel pouco conhecido no próprio desenvolvimento econômico" (Abramovay, Gazeta Mercantil, 12 de abril de 2001, página A3). 
parece óbvio que o uso que se faz do território possui um sentido conceitual e heurístico, indubitavelmente importante para os estudiosos dos processos sociais. Neste caso, vale a interrogação: quais seriam as possibilidades ou as restrições para se utilizar o território como termo ou noção de referência no campo das políticas públicas e das ações práticas com fins operacionais?

Talvez a resposta à indagação possa advir das próprias recomendações da Geografia, especialmente do que diz Milton Santos (1994, p. 15), para quem o retorno bem sucedido do território se dá pelo legado da modernidade incompleta, através de "seu uso e não pelo território em si mesmo"; isto é, superaram-se os fundamentos do território exclusivo do Estado-Nação, relacionado ao sentido que lhe emprestara a tradição ratzeliana, prevalecendo a análise das relações flexíveis que ocorrem neste espaço. ${ }^{5}$ Na mesma direção, Becker informa que o território como conceito explicativo geográfico retorna às discussões acadêmicas sob nova acepção, "como um produto produzido pela prática social, e também um produto consumido, vivido e utilizado como meio, sustentando, portanto a prática social" (1983, p.8).

Mas, para superar os limites e a controvérsia entre o uso conceitual e heurísitico do território e sua pertinência como unidade de referência empírica e normativa, o pragmatismo prudente recomendaria recorrer à solução proposta pelos geógrafos de utilizar o que chamam de "articuladores analíti$\cos ^{\prime \prime}$, que seriam as escalas e a noção de poder. Em outro trabalho, (Blume e Schneider, 2003), foram discutidos em maior detalhe as possibilidades de se utilizar a análise escalar (micro, meso, macro ou local, regional, nacional, internacional, etc.) para exercícios de aproximação e de superposição de dimensões que podem estar contempladas em um mesmo território. No que se refere ao poder, sua capacidade de articulação dos espaços está intrinsecamente relacionada ao seu caráter transcendente, o que faz do território uma arena de disputas de visões de mundo, interesses de atores e

5 Para Milton Santos, o território compreende, ao mesmo tempo, forma e conteúdo; como forma, o território é o espaço concreto, físico; como conteúdo é o espaço objetivamente apropriado pelo homem, usado, construído, enfim, o território éo espaço habitado (1994, p. 16) 
alianças políticas visando o exercício do poder através da dominação.

Embora haja soluções para superar as restrições e os limites conceituais apontados, o uso normativo do território requer ponderações. Primeiro, deve-se reconhecer que não é possível uma adaptação pura e simples do seu sentido conceitual e analítico para fins normativos e operacionais, há que fazer mediações e adequações. Segundo, como referido, o pragmatismo prudente parece recomendar aos usuários não-acadêmicos que deixem de lado as questões teóricas e heurísticas e passem a utilizar o território ou a abordagem territorial na perspectiva do desenvolvimento rural. Nessa perspectiva, conforme indicado na seção anterior, a abordagem territorial assume a função de uma ferramenta para se pensar o planejamento e a intervenção no tecido social a partir de alguma escala, quer seja local, regional, microrregional, etc. Neste caso, o território passaria a ser uma unidade de referência, um nível de operação e agregação adequado para operar o planejamento de ações governamentais e políticas públicas que promovam mudanças e transformações múltiplas no espaço social.

Esta definição conferiria utilidade normativa e prática ao território, passando-se à entendê-lo como a unidade de referência para a implementação e gestão das ações intervencionistas. Este tipo de orientação poderá ser particularmente útil para aqueles que pretendem fazer uso normativo do território, na realidade de um referencial territorial, mas partindo de definições abstratas e conceituais. Este tipo de hesitação permeia o recém lançado Documento de Referência para um Programa Territorial de Desenvolvimento Rural Sustentável, elaborado pelo IICA, sob os auspícios do MDA, CNDRS e NEAD. Felizmente, ao final do documento, encontrase uma definição operacional para o território, que é entendido como

um espaço físico, geograficamente definido, geralmente contínuo, compreendendo cidades e campos, caracterizado por critérios multidimensionais, tais como o ambiente, a economia, a sociedade, a cultura, a política 
e as instituições, e uma população, com grupos sociais relativamente distintos, que se relacionam interna e externamente por meio de processos específicos, onde se pode distinguir um ou mais elementos que indicam identidade e coesão social, cultural e territorial.

Especificamente, os territórios rurais são acrescidos da necessidade de "predominância de elementos rurais" e da inclusão dos "espaços urbanizados que compreendem pequenas e médias cidades, vilas e povoa$\operatorname{dos}^{\prime \prime}\left(2003\right.$, p. 20). ${ }^{7}$

Enfim, não há por que imaginar que a discussão sobre o uso normativo e prático da abordagem territorial deva ser revestida de incógnitas teóricas e conceituais em torno das quais nem mesmo os acadêmicos estabeleceram consenso ao longo de anos de discussão e pesquisa. Não se trata, obviamente, de propor uma ruptura radical entre o que Bourdieu chamaria de "campo" acadêmico e normativo mas, sobretudo, de oxigenar e dar sentido prático (sens pratique) a uma determinada categoria que é ubíqua.

Mas há ainda uma segunda questão, geralmente pouco referida e insuficientemente contemplada na discussão normativa e prática, que se refere às articulações externas dos territórios, especialmente os rurais. Embora as definições incorporem a visão de que o território engloba atividades de setores econômicos diferentes (agricultura, indústria, etc.) e supera a clivagem rural-urbano, não são ainda suficientemente esclarecidas as relações dos territórios com a dinâmica social e econômica mais ampla. Em face da novidade que representa a discussão sobre a abordagem territorial e, talvez, uma certa necessidade de delimitar-se de forma diferenciada em relação aos outros aportes, tem sido deixado de lado o fato de que os territórios não são ilhas, pois se situam em meio a um contexto nacional e internacional que possui uma dinâmica social, econômica, cultural, política,

6 “Ambiente natural pouco modificado e/ou parcialmente convertido a atividades agro-silvo-pastoris; baixa densidade demográfica; população pequena; base na economia primária e seus encadeamentos secundários e terciários; hábitos culturais e tradições típicas do universo rural".

7 No documento, esta visão é referida como integradora e estimuladora da coesão social nos espaços; também privilegia a esfera prática e normativa, sugerindo a utilização das noções de ordenamento e planejamento para implantação da abordagem territorial. 
ou de outra natureza, que é sistêmica e que influencia, pressiona e delimita os espaços de ação dos agentes.

Neste sentido, talvez valha a pena uma sugestão interessante de Reis (1992), que parece sugerir uma solução inteligente ao problema da intermediação entre o local e o extra-local. Na sua opinião,

a análise local (entendido como território) é uma tentativa de compreensão dos processos de articulação sócioeconômica que diferenciam os espaços e definem as condições localizadas de organização da economia. Ao passar-se da noção de espaço econômico equivalente à de uma geografia abstrata, modelada pelos preços ou delineada por rigorosos cálculos espaciais só acessíveis aos agentes econômicos que podem tomar decisões de grande escala, para uma idéia de territórios (espaços e lugares) com capacidade de estruturação interna, relativiza-se bastante a faceta estritamente econômica dos fenômenos e obtém-se, porventura, uma nova percepção das articulações espaciais da economia (...) Podemos sem dúvida considerar que a análise dos espaços locais se converte, em muito, numa análise das articulações econômicas que Ihes conferem espessura e particularidades $\left(1992\right.$, p. 81). ${ }^{8}$

Esta idéia de Reis, de definir os territórios como espaços de mediação e articulação entre o local e o ambiente externo (que pode ser nacional, internacional, enfim, multiescalar) retoma uma cobrança analítica, que fora apresentada por Raffestin (1986; 1987), no sentido de que não se pode falar livremente de territórios sem fazer referência às escalas. Do contrário, a noção de território acaba restringindo-se, como já enfatizado, a uma idéiareferência para o planejamento ou ordenamento, assumindo uma função estritamente prática e normativa ou, em outro sentido, acaba substituindo a

8 Segundo Reis (1992, p. 81) “a análise do local não se confunde com uma análise localista. O local articula-se com os processos globais de regulação econômica e há espaços de mediação entre estas duas esferas que, aliás, se não organizam segundo um mero esquema topológico, mas sim segundo um esquema relacional". Ver também Reis (1985; 1988). 
noção de local ou esfera endógena, resgatando a noção de região, utilizando-a como um simples sinônimo de espaço inferior. Se assim for, não será demasiado que, em pouco tempo, os usuários da abordagem territorial sejam acusados de modismo ou, para usar a feliz expressão de Schejtman e Berdegué (2003), "seguir haciendo más de lo mismo" com outra denominação.

No Brasil, já há inclusive autores que vêem com cautela a possibilidade de formular um modelo de desenvolvimento calcado no princípio da localidade ou da territorialidade. Graziano da Silva (2002), por exemplo, salienta que, na maioria dos espaços rurais brasileiros, a debilidade da organização social dos atores sociais é um obstáculo que não pode ser negligenciado. Para Graziano da Silva, a falta de participação dos beneficiários é apresentada muitas vezes como um fato inevitável, especialmente nos projetos que envolvem populações em contextos de pobreza extrema, como ocorre na maioria das regiões rurais e/ou periféricas do nosso país. A verdade é que o Estado, nos seus diferentes níveis, não se encontra aparelhado para oferecer respostas às questões levantadas pelas populações locais. E não se trata apenas das carências de meios técnicos, recursos humanos ou financeiros suficientes para enfrentar esses problemas. Trata-se, na realidade, na opinião deste autor, de um tipo de sociedade civil cuja organização social e institucional é frágil e, em muitas situações, virtualmente inexistente.

Navarro (2001), por sua parte, também oferece ressalvas ao livre intercambiamento entre a noção de desenvolvimento local/território e desenvolvimento rural, acentuando que a idéia de localidade, tal como vem sendo utilizada, é largamente tributária à disseminação das estratégias de "ação local" (do tipo pensar globalmente e agir localmente), que no início eram o foco de intervenção de ONGs e, aos poucos, passou a ser assimilada por outras instâncias como o próprio Estado. Portanto, para esse autor, não há por que imaginar que a mera descentralização de iniciativas governamentais, ou mesmo a mudança de enfoque, privilegiando o local ou o território, possa implicar um processo em que se passe a ter um desenvolvimento rural de nova estirpe. 
Não obstante estas ressalvas, resta-nos pensar os territórios como o centro de articulações e mediações entre a diversidade e a heterogeneidade da sociedade local com o ambiente externo, tal como sugerido por José Reis. O território não seria, portanto, autônomo e tampouco inteiramente dependente do exterior, mas o resultado concreto e material do processo de articulação e mediação.

A terceira questão, decorrente da anterior, refere-se à necessidade, então, de qualificar as relações dos territórios, especialmente os rurais, com o ambiente externo, já que se considera esta uma falha das discussões recentes sobre o assunto. Neste sentido, é importante não perder de vista o que foi mencionado na primeira parte deste texto, quando se afirmou que uma das razões que deram relevo e ajudaram a expor as virtudes da abordagem territorial foram, exatamente, os efeitos do processo de globalização. Como se disse, contraditoriamente (pelo menos aparentemente), a globalização acaba realçando o papel das dinâmicas locais e territoriais.

Tomando-se esta afirmação como verdadeira, o que se percebe com relativa facilidade, é que o processo de globalização que produz como efeito a revalorização dos territórios não é homogêneo e simétrico. Pelo contrário, conforme já havia destacado Marsden (1992), ele é assimétrico e desigual. Coincidindo com esta avaliação, Saraceno (2003) indica que o aprendizado recente que se observa na Europa, mediante estudo das experiências de desenvolvimento territorial bem sucedidas, indicam que não há uma regra ou receita única neste processo. A autora enfatiza que a revalorização dos territórios rurais pode ocorrer por caminhos variados, sejam eles baseados nas estratégias privadas (empresas ou agentes) ou de natureza pública-governamental (políticas públicas, etc.). Em ambos os casos, a semelhança fica por conta do fato de que, em quase todas as experiências, prevalece a diversificação e combinação intersetorial e não a especialização e a homogeneidade. Ou seja, os territórios que conseguem uma integração 
dinâmica com o sistema social e econômico caracterizam-se por estarem assentados em um milieu heterogêneo e diversificado.

Como resultado e lição, segundo a autora, a experiência européia (referido-se, neste caso, aos programas do desenvolvimento rural baseados no enfoque territorial deste continente, tais como o programa LEADER) tem mostrado que as transformações que ocorrem no meio rural e que levam à diversificação econômica dos territórios, asseveram e tornam ainda mais complexo seu intercâmbio com o exterior. ${ }^{9}$

Neste sentido, no intuito de qualificar os modos e as particularidades com que ocorre o processo de intermediação dos territórios rurais com o ambiente externo é que se podem identificar seis formas distintas (provavelmente haja outras mais) através das quais ocorre esta articulação e mediação dialética porque não se trata de uma via de sentido único:

a) a forma tradicional, através da produção agrícola e do fornecimento de matérias-primas, ainda reveste-se de importância fundamental para a sociedade, especialmente quando se leva em consideração o papel das cadeias agroindustriais e do sistema agroalimentar para muitas localidades e territórios rurais. Malgrado as restrições de ordem ocupacional, uma vez que é sabido que o setor agrícola, assim como os demais ramos da economia capitalista, estão submetidos a um padrão intenso e constante de evolução tecnológica que caminha na direção inversa ao crescimento do emprego. Mesmo assim, não se pode desconhecer o fato de que vários territórios garantem o essencial de sua base produtiva e econômica através de ligações externas com empresas do setor agroalimentar. Para muitos desses territórios, alterar suas características sociais e econômicas dependerá muito mais dos rearranjos globais do que dos elementos propriamente endógenos. O que não significa que não

9 “La situación actual de zonas rurales está determinada por los dos procesos principales que determinan la evolución futura de las zonas rurales: la diversificación interna por una parte y la multiplicación de las formas de integración exterior, por otra. El resultado de estos dos procesos ha reducido la dependencia del centro urbano más cercano y la importancia del factor distancia" (Saraceno, 2003, p. 11). 
seja possível, e até mesmo desejável, modificar o padrão histórico destas relações. Apenas indica que, neste caso, a natureza das "amarrações" entre o local e o global, pende muito mais favoravelmente para o lado da dimensão externa dos territórios;

b) a necessidade de repensar a dinâmica das relações rural-urbanas ou campo-cidade. Também esta forma de relação do rural com as aglomerações populacionais urbanas não representa algo inteiramente novo. Contudo o que está sendo criticado e superado é a concepção de que a única forma de relação do rural com o urbano seria mediante o fornecimento de mão-de-obra e de que a evolução desta relação conduziria, fatalmente, a uma incorporação ou absorção do rural pelo urbano (seria a chamada "urbanização do campo", também chamada de rurbanização). Ao contrário desta visão residual do rural, assentada na dicotomia rural-urbana (contradição, para muitos), já há vários estudos indicando a necessidade de se passar para uma visão complementar, que propugna uma inter-relação positiva entre as cidades e os espaços urbanos em relação ao meio rural que forma seu entorno (Veiga, 2001; Ortega, 1998; Schejtman, 1998, etc.);

c) através da importância da pluriatividade das famílias que residem no rural e trabalham em atividades não-agrícolas fora da propriedade e, não raro, do próprio espaço rural. Segundo Berdegué, Reardon e Escobar (2001, p.184) o emprego rural não-agrícola é atualmente responsável por cerca de $40 \%$ das rendas dos habitantes rurais da América Latina. Segundo esses autores, a importância das atividades rurais não-agrícolas está no fato de que elas podem integrar soluções para três grandes problemas do mundo rural latino-americano, que são a pobreza rural, a transformação do setor agropecuário e a modernização técnico-produtiva. No Brasil, as pesquisas Projeto Rurbano demonstraram que as pessoas com domicílio rural, ocu- 
padas em atividades não-agrícolas, aumentaram de 3,06 milhões em 1981 para 3,49 em 1992, chegando a 4,62 milhões de pessoas em 1999. Isto representa um aumento de mais de 1,5 milhão de postos de trabalho no período de duas décadas. Segundo os cálculos de Del Grossi e Graziano da Silva, o número de famílias rurais em que há membros que estão ocupados em atividades não-agrícolas alcança algo em torno de 1,8 milhão (cerca de $24 \%$ ) do total de 7,5 milhões de domicílios rurais existentes no país (1998, p. 36). Quando considerados também os domicílios urbanos (que somam um total de 3,4 milhões, dos quais cerca de 2 milhões são também pluriativos) onde pelo menos um de seus membros trabalha na agricultura (este é o caso dos trabalhadores que residem em áreas definidas como urbanas mas que têm seu trabalho e ocupação em atividades agrícolas), esta proporção sobe para 35\% do conjunto das famílias brasileiras que podem ser consideradas pluriativas. Neste sentido, a viabilização social e econômica de muitos territórios, por mais dependentes que sejam da atividade agrícola, passa a ser fortemente influenciada pela sua capacidade de gerar outras oportunidades de ocupação e trabalho, estimulando o aparecimento da pluriatividade entre as famílias rurais;

d) por intermédio das novas relações entre produtores e consumidores. É cada vez mais notável, mesmo em sociedades não desenvolvidas como a brasileira, que está um curso, um processo de redefinição das relações produção-consumo, amplamente assentado na questão da qualidade dos alimentos e na observância às formas sustentáveis de sua obtenção. Apesar de ainda hegemônicos, os circuitos de escoamento da produção agrícola via mercados cativos oferecidos pelas grandes cadeias agroindustriais, já é possível identificar pequenas mudanças, iniciativas de organismos públicos (os programas de compras governamentais de alimentos para pro- 
jetos sociais, que recém se iniciam, são um exemplo) e da própria sociedade civil (organização de associação de consumidores, donas-de-casa, feiras livres, etc.) que tencionam e buscam um novo padrão de acesso a produtos alimentares de qualidade, produzidos segundo as prerrogativas da sustentabilidade ambiental. Por este viés, é possível prever que haja possibilidades para a ação concertada e mediatizada por atores e instituições territoriais. Este tipo de iniciativa, apesar de representar uma potencial forma inovadora de relação dos territórios com seu entorno, haverá de contar, talvez por largo período de tempo, com o apoio fundamental do Estado e/ou outras instituições para que consiga superar as barreiras e os limites dos mecanismos tradicionais. Neste sentido, ao invés de se pensar na autonomização do local e do território, o que se requer é justamente o contrário, que é o reforço da articulação do local com o exterior;

e) através da revalorização urbana do rural, não apenas através do incremento dos interesses dos habitantes citadinos pela apropriação material do que o rural produz. Ao contrário, o que se busca cada vez mais no rural é valorizar as "amenidades" e os "bens nãotangíveis" (Cazella, 2001). O interesse das populações, que residem fora dos espaços rurais, por estes territórios, expressa-se em diferentes sentidos. Primeiro, pela ampliação do tempo livre e pelas melhorias nos meios de comunicação, o que cria um público e uma demanda crescente por atividades diferenciadas, não-rotineiras. Segundo, pelo interesse da população em geral em estabelecer formas de contribuir ativamente em ações de preservação e valorização do meio ambiente, o que torna os territórios rurais uma alternativa evidente. Terceiro, interesses pelo rural associados ao patrimônio histórico, paisagístico, cultural (étnico, gastronômico, etc.), ocasionando um novo fluxo de interações. Quarto, 
revalorização social do rural através do incremento populacional que se pode dar pelo retorno de populações de aposentados e antigos moradores, que retornam ao rural prioritariamente como um refúgio em relação ao urbano. Quinto, através da descentralização de atividades empresariais, o que ocasiona deslocamentos demográficos para o rural em função do processo de relocalização industrial. Por certo haveria outros exemplos a oferecer além destes, mas o que vale destacar é que, neste particular, as relações do rural (ou dos territórios rurais) com o exterior passam a ocorrer basicamente pelo incremento dos serviços de toda ordem;

f) finalmente, articulações exteriores dos territórios rurais que se assentam sobre a dimensão sociocultural, pois não há como negar a influência determinante dos meios de comunicação e dos padrões de consumo da sociedade (pós-moderna, como definiram alguns sociólogos - Giddens, 1991). Embora guardem autonomia e especificidades, no espectro social e cultural é que verdadeiramente se percebem as interfaces que existem dos locais (lugares), por mais remotos que sejam, com o modo de vida e as visões de mundo globais. Levar em conta esta dimensão pode ser de grande valia particularmente aos formuladores de políticas públicas, pois são estas influências externas que orientam as representações simbólicas e conferem sentido aos desejos de muitos jovens que vivem em áreas rurais eqüidistantes dos locais onde o acesso a estes mesmos objetos se torna factível. Entretanto, é preciso não se iludir, quando os técnicos e mediadores externos imaginam que estão levando a solução adequada ou recomendada às condições locais dos habitantes rurais, não raro são surpreendidos com a manifestação destes de que seu desejo era outro (isto quando lhes é facultada a oportunidade da palavra). Neste sentido, pode-se lembrar que a relação local-global ou território-contexto externo traz 
consigo o que Bourdieu chamou de violência simbólica, pois o poder da imposição de uma determinada ação ou visão de mundo não deixa de ser (mesmo involuntariamente) uma arbitrariedade histórica que acaba reforçando a posição e o próprio poder dominante, que em geral é o externo ou o global, sobre os indivíduos e seus territórios.

\section{Referências}

ABRAMOVAY, R. Agricultura familiar e desenvolvimento territorial. Brasília: MDA, NEAD, Consultoria IICA 940/98, 1998.

ABRAMOVAY, R. O capital social dos territórios: repensando o desenvolvimento rural. Economia Aplicada. v. 4, n² 2, abril/junho. 2000.

ABRAMOVAY, R. Relatório Institucional da Secretaria da Agricultura Familiar. Brasília: PNUD, Projeto BRA-98/012, junho/2002, Relatório de Pesquisa.

BAGNASCO, A. Le Developpement diffus: le modèle Italien. In: SACHS, I. (Dir.). Quelles Villes, Pour Quel Developpement? Paris: PUF, 1996. p.191-213.

BAGNASCO, A., TRIGLIA, C. La Construction Sociale du Marché: Le défi de la Troisième Italie. Paris: Juillet/Éditions de L'ENS-Cachan, 1993.

BECKER, B. O uso político do território: questões a partir de uma visão do terceiro mundo. In: BECKER, B.; COSTA, R.H.; SILVEIRA,C.B. (Orgs.).Abordagens políticas e espacialidade. Rio de Janeiro: UFRJ, p. 1-8, 1983.

BERDEGUÉ, J.L; REARDON, T. e ESCOBAR, G. La creciente importancia del empleo y el ingreso rurales noagricolas. In: ECHEVERRIA, R.G (Ed.). Desarrollo de las economías rurales. Washington: Banco Interamericano de Desarrollo - BID, 2001.

BLUME, R. SCHNEIDER, S. Do território ao desenvolvimento territorial: In: CONGRESSO BRASILEIRO DE ECONOMIA E SOCIOLOGIA RURAL, XLI, Juiz de Fora, MG, 27 a 30 de julho de 2003. Anais... Brasília: SOBER, 2003. CD-Rom.

BOISIER, S. El desarrolo territorial a partir de la construccion de capital sinergético. Revista Redes, Santa Cruz do Sul, RS, Edunisc, V.4, nº1, p.61-78, jan/ab. 1999.

CAMPANHOLA, C. e GRAZIANO DA SILVA, J. Desenvolvimento Local e a Demo- 
cratização dos Espaços Rurais. Cadernos de Ciência e Tecnologia, Brasília.17(1):1140 (jan/abr), 2000.

CASTELLS, M. A sociedade em rede. A era da informação: economia, sociedade

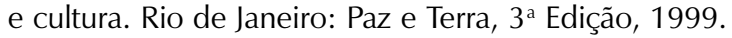

CAZELLA, A. A. Revitalização das zonas rurais marginalizadas: a construção social da multifuncionalidade agrícola na França. In: XXIX Congresso da SOBER. Recife, 2001. Anais... Brasília: SOBER, 2001. 1 CD-Rom, 2001.

COUTINHO, L. Nota sobre a natureza da globalização. Economia e Sociedade, Campinas, SP, no 4, p.21-6, jun. 1995.

DEL GROSSI, M. E. e GRAZIANO DA SILVA, J. A pluriatividade na agropecuária brasileira em 1995. Estudos Sociedade e Agricultura, no 11, R.J., CPDA, 1998.

ECHEVERRIA, R.G (Ed.) Desarrollo de las economías rurales. Washington: Banco Interamericano de Desarrollo - BID, 2001.

ELLIS, F. BIGGS, S. Evolving themes in rural development - 1950s-2000s. Development Policy Review, 19 (4): 437-448, 2001.

ELLIS, F. Household strategies and rural livelihood diversification. The Journal of Development Studies, 35 (1): 01-38, 1998.

ELLIS, F. Rural livelihoods and diversity in developing countries. Oxford: Oxford University Press, 2000.

GIDDENS, A. As conseqüências da modernidade. São Paulo: Editora Unesp, $2^{\text {a }}$ Edição,1991.

GOODMAN, D., WATTS, M. (Eds.). Globalizing Food: agrarian questions and global restructuring. London: Routledge, 1997.

GRAZIANAO DA SILVA, J. Quem precisa de uma estratégia de desenvolvimento? Textos para Discussão, Brasília, NEAD, CNDRS, MDA, no 02, 2002.

GRAZIANO DA SILVA, J. O novo rural brasileiro. Campinas: UNICAMP, Instituto de Economia, 1999. (Coleção Pesquisas, 1).

GRAZIANO DA SILVA, J. O desenvolvimento local sustentável: um novo desafio para os países retardatários. In: XXXVIII Congresso da SOBER e X Congresso Mundial de Sociologia Rural (IRSA). Anais... Brasília: SOBER, CD-Rom, 2000. 
HAESBAERT, R. Des-territorialização e identidade: a rede "gaúcha" no nordeste. Niterói: EdUFF, 1997.

HAESBAERT, R. Territórios Alternativos. Niterói: EdUFF e São Paulo: Contexto,2002.

HARVEY, D. Condição pós-moderna. São Paulo: Loyola, 1993.

MARSDEN, T. Exploring a Rural Sociology for the Fordist Transition: incorporating social relations into economic restructuring. Sociologia Ruralis, V.32, no 2/3, p.209230, 1992.

MARSDEN, T., et alii. Constructing the Countryside. Oxford: Westview Press, 1993.

MARSDEN, T., LOWE, P., WHATMORE, S. (Eds.). Rural Reestructuring: global process and their responses. London: David Fulton Publishers, 1990.

MDA/SDT/CONDRAF. Referências para um programa territorial de desenvolvimento rural sustentável. Brasília, IICA, Documento do trabalho, versão de setembro de 2003.

MÉO, G. Di. Géographie sociale et territoires. Paris: Éditions Nathan, 1998.

NAVARRO, Z. Desenvolvimento rural no Brasil: os limites do passado e os caminhos do futuro. Revista Estudos Avançados, São Paulo, USP, Vol. 16, no 44, 2001.

NAVARRO, Z. Do "mundo da roça" ao mercado: mudanças recentes e o desenvolvimento agrário no Sul do Brasil. Brasília: NEAD, Relatório de pesquisa, 2002.

NAVARRO, Z. Manejo de recursos naturais e desenvolvimento rural: um estudo comparativo em quatro estados brasileiros (lições e desafios). Relatório ao Banco Mundial, 1999.

OCDE. Organisation de Coopération et Developpement Économique. Indicateurs Territoriaux de l'Emploi: le point sur le développement rural. Paris: Editions de OCDE, 1996.

ORTEGA, L. Los vínculos rurales con ciudades intermedias: sínteses de estudios de caso. Cepal, Chile, Documento de Trabajo no 1835.

PECQUEUR, B. (ed.) Dynamiques Territoriales et Mutations Économiques. Paris: L' Harmattan, 1996.

PECQUEUR, B. Territoire, Territorialité et Developpement. In: Coloque Industrie et Territoire, IREPD, Grenoble, 20-22 octobre 1992. 
PIORE, M., SABEL, C. The Second Industrial Divide: possibilities for prosperity. New York: Basic Books, 1984.

PLOEG J.D. van der et alii. Rural Development: from practices and policies towards theory. Sociologia Ruralis, Netherlands, 40 (4): 391-407, 2000.

PLOEG J.D. van der and RENTING, H. Impact and potential: a comparative review of European rural development practices. Sociologia Ruralis, Netherlands, 40 (4): 529-543, 2000.

PLOEG, J.D. van der.; VAN DIJK, G. (eds.). Beyond modernization: the impact of endogenous rural development. Netherlands assen, Van Gorcun, 1995.

RAFFESTIN, C. Por uma geografia do poder. São Paulo: Ática, 1993.

RAFFESTIN, C. Repères pour une théorie de la territorialité humaine. Cahier du Groupe Réseaux, no 07, p. 263-279,1987.

RAFFESTIN, C. Territorialité: concept ou paradigme de la geograpie sociale? Geographica Helvetica, no 02, p. 91-96, 1986.

REARDON, T. e BERDEGUÉ, J.A. La rápida expansión de los supermercados en América Latina: desafíos y oportunidades para el desarrollo. Banco Interamericano de Desarrollo - BID (Departamento de Desarrollo Sostenible, Unidade de Desarrollo Rural), Washington, junio, 2003.

REIS, J. Modos de industrialização, força de trabalho e pequena agricultura. Revista Crítica de Ciências Sociais, n ${ }^{\circ 5}$ 15/16/17, Portugal, 1985.

REIS, J. Os Espaços da Indústria. A regulação econômica e o desenvolvimento local em Portugal. Portugal: Edições Afrontamento, 1992.

REIS, J. Território e sistemas produtivos locais: uma reflexão sobre as economias locais. Revista Crítica de Ciências Sociais, nํ2 25/26, Portugal, 1988.

SANTOS, M. O retorno do território. In: SANTOS, M et al. (Orgs.): Território: Globalização e fragmentação. São Paulo: Hucitec/Anpur, p. 15 - 20, 1994.

SARACENO, E. Urban-rural linkages, internal diversification and external integration: a european experience. Políticas Agrícolas, Numero Especial [Memoria del Seminario Interrelación Rural-Urabna y Desarrollo Descentralizado, 1997], Taxco/México, 1998. 
Sociologias, Porto Alegre, ano 6, no 11, jan/jun 2004, p. 88-125

SARRACENO, E. La experiencia europea de desarrollo rural y su utilidad para el contexto latinoamericano. Grupo de Asesores Políticos (Group of Policy Advisers), Comisión Europea, Documento de Trabajo, 2003.

SCHEJTMAN, A. Alcances sobre la articulación rural urbana y el cambio institucional. Taxco, Mexico, Políticas Agrícolas, Número Especial, 1998.

SCHEJTMAN, A. BERDEGUÉ, J. Desarrollo territorial rural. RIMISP, Santiago/Chile, febrero, 2003, $54 \mathrm{p}$.

SCHNEIDER, S. A Pluriatividade na Agricultura Familiar. Porto Alegre: Editora da UFRGS, 2003.

SOUZA, M.J.L. O território: sobre espaço e poder, autonomia e desenvolvimento. In: CASTRO, I.E.; GOMES, P.C.C. e CORRÊA, R.L. (Orgs.). Geografia: conceitos e temas. Rio de Janeiro: Bertrand Brasil, 1995.

VÁSQUEZ BARQUERO, A. Desenvolvimento endógeno em tempos de globalização. Porto Alegre: Ed. UFRGS/FEE, 2002.

VEIGA, J.E. O Brasil Rural ainda não encontrou seu eixo de desenvolvimento, Estudos Avançados, 43, Setembro-Dezembro 2001, pp. 101-119.

VEIGA, J.E. Desenvolvimento rural: o Brasil precisa de um projeto. Texto para CONTAG,1998. 55 p.

VEIGA, J.E. A face territorial do desenvolvimento. Anais do $27^{\circ}$. Encontro Nacional de Economia, Belém, 8-10 de Dezembro de 1999, volume II, pp. 1301-1318, 1999.

VEIGA, J. E; FAVARETO, A. AZEVEDO, C.M.A.; BITTENCOURT, G.; VECCHIATTI, K.; MAGALHÃES, R. e JORGE, R. O Brasil Rural precisa de uma estratégia de desenvolvimento, Série Textos para Discussão, número 1, NEAD, Agosto 2001.

Recebido: 10/01/2004

Revisado: $21 / 03 / 2004$

Aceite final: 31/03/2004 
Sociologias, Porto Alegre, ano 6, no 11, jan/jun 2004, p. 88-125

\section{Resumo}

A discussão sobre o desenvolvimento rural de determinadas regiões e suas articulações externas é entendida como exemplo de uma temática que é retomada no Brasil por força das reflexões cada vez mais interessadas em compreender a diversidade de rotas que segue o processo de desenvolvimento e as raízes sociais, econômicas e culturais que explicam essa diversidade. Na primeira seção do trabalho analisam-se os condicionantes mais gerais do processo de reestruturação da economia e da sociedade, buscando identificar as relações e as mediações entre os processos locais e as mudanças decorrentes da reestruturação do capitalismo contemporâneo. Na segunda seção, discute-se o novo enfoque do desenvolvimento rural, abordagem apoiada no alargamento da abrangência espacial, ocupacional e setorial do rural. Na terceira seção, pretende-se indicar a necessidade de consolidar o deslocamento da idéia de região para a de território, resgatando-se tanto as implicações e resistências a esta operação que vem da geografia como as indicações de alguns estudiosos, organismos internacionais e governos que fazem um uso normativo e operacional da abordagem territorial para indicar um novo enfoque sobre o desenvolvimento regional. À luz destas discussões, na quarta e última seção, pretende-se analisar as articulações e intermediações das dinâmicas locais e territoriais com o ambiente externo, aqui entendido como o contexto econômico e societário em que transcorrem os processos de mudança social.

Palavras-chave: desenvolvimento rural, abordagem territorial, desenvolvimento regional. 